\title{
Chirping Techniques to Maximize the Power- Handling Capability of Harmonic Waveguide Low-Pass Filters
}

\author{
Fernando Teberio, Ivan Arregui, Adrian Gomez-Torrent, Israel Arnedo, Magdalena Chudzik, \\ Michael Zedler, Franz -J. Görtz, Rolf Jost, Txema Lopetegi, and Miguel A. G. Laso
}

\begin{abstract}
A novel chirping technique is applied to the design of very high-power waveguide harmonic low-pass filters. The technique could be used, for instance, to avoid multipactor testing in multicarrier systems such as the output multiplexer of a communications satellite. The novel chirped filter shows low insertion loss, all-higher order mode suppression, and broad stopband rejection up to the third harmonic. The paper focuses on the maximization of the filter power-handling capability without affecting its excellent frequency behavior. Given a certain frequency response, the E-plane mechanical gap of the structure and the length (in the propagation direction) of the waveguide sections between its constituent bandstop elements can be considered to improve the high-power behavior. However, the power performance may be not sufficient yet in some applications if we wish, for instance, multipactor testing to be avoided. This becomes feasible by chirping the length (in the propagation direction) of the bandstop elements. An example for Ku band is discussed for relevant frequency specifications. An improvement from around $8 \mathrm{~kW}$ (non-chirped filter) to more than $100 \mathrm{~kW}$ (chirped filter) is obtained. As a reference, the equivalent waffle-iron filter can handle only $0.15 \mathrm{~kW}$. Such highpower threshold levels have been never reported before for such kind of filters.
\end{abstract}

Index Terms - Harmonic filters, multipactor, low-pass filters, multicarrier, rectangular waveguide.

\section{INTRODUCTION}

$\mathrm{L}$ OW insertion loss and high-power handling capability are the main features of the rectangular waveguide technology. Within this technology, low-pass filters have been used for a long time in numerous applications [1]-[3]. For this reason, it would be useful to have a flexible design method of low-pass filters which could be easily adapted to a multitude of different scenarios, in particular with different requirements in terms of power handling. For instance, modern satellite payloads are operated with an increasing number of communication channels and still increasing power level per

This work was supported by the Spanish Ministry of Science and Innovation under Project TEC 2014-55735-C3-R.

F. Teberio, I. Arregui, A. Gomez-Torrent, I. Arnedo, M. Chudzik, T. Lopetegi, and M. A. G. Laso are with the Electrical and Electronic Engineering Department, Public University of Navarre, Pamplona 31006, Spain (e-mail: fernando.teberio@unavarra.es).

M. Zedler, F.-J. Görtz, and R. Jost are with Tesat-Spacecom GmbH \& Co. KG, Backnang 71522, Germany. channel [3]. In fact, the peak power due to multiple carriers operating simultaneously compromises the output multiplexer and, more precisely, the output low-pass filter. Specifically, with the growing development of high-power payloads in the 12 to $20 \mathrm{~kW}$ range, the power at the output of the output multiplexer can now reach several $\mathrm{kW}$ [4]. The requirements imposed in terms of power handling can make very difficult and costly to fully assess multipactor experimentally in these filters due to the high power levels involved at high frequencies. Therefore, it would be very useful for the space industry to develop a method to design filters which could handle at least $6 \mathrm{~dB}$ above the equivalent multicarrier peak power to avoid testing the devices, following the recommendation in [5]. For instance, if we assume a multicarrier system with 12 carriers of $120 \mathrm{~W}$ each, the peak power that the filter would have to withstand is, in the most pessimistic scenario [6], $17.3 \mathrm{~kW}\left(120 \times 12^{2}\right)$. According to [5], the filter should handle in analysis at least $70 \mathrm{~kW}(6 \mathrm{~dB}$ above $17.3 \mathrm{~kW}$ ). Getting these extreme values is not possible with the proposals made in the literature up to now. However, it would make an important impact on industry.

The corrugated waveguide filter is a classical solution for low-pass filters when low-loss, compact size, and an easy manufacturing are required [7]. However, there are some intrinsic trade-offs in its design, such as the fact that it is not possible to achieve high-power behavior and a wide stopband simultaneously. Over the last years, some techniques based on quarter-wave stubs have appeared in the literature. In [8], an alternative to the classical E-plane corrugated filter was proposed for very wide rejected bands and high-power applications. These filters are based on E-plane quarter-wave stubs following a smooth (sinusoidal-like) profile which are used to maximize the high-power behavior of the filter [9], unfortunately making the manufacturing by ComputerControlled Milling (CCM) more complicated. Moreover, long windowed sections at the input and output ports are employed to achieve the matching of the filter, affecting the final size and, consequently, the insertion loss. Recently, in [10], the possibility of achieving very steep slopes in the fundamental $\mathrm{TE}_{10}$-mode frequency response along with a very wide rejected band and a drastic reduction in terms of insertion loss and size in comparison with the classical corrugated filter has been demonstrated using an easy-to-manufacture topology 
based also on quarter-wave stubs. Although the filter in [10] permits also high multipactor threshold levels, the suppression of the spurious higher-order modes still remains a problem.

Indeed, spurious modes may unfortunately appear due, for example, to misalignments between waveguides [11]. In applications where their suppression is mandatory, the abovementioned filters are not useful. The spurious passbands due to the higher-order $\mathrm{TE}_{\mathrm{n} 0}$ modes are well reported in [12], and can be perfectly suppressed with classical solutions such as waffle-iron [13] or evanescent-mode filters [14]. Some improvements of the classical waffle-iron filter were studied in [15]-[17] where wider passbands and higher powerhandling capabilities were achieved in comparison with [13]. However, the minimum mechanical gap in the waffle-iron filters is directly connected with the maximum frequency of the fundamental-mode rejected band. Thus, if the maximum frequency to be rejected is high, the E-plane mechanical gap will be small and, therefore, high-power operation will not be allowed. In recent times, a high-power low-pass filter with suppression of the higher-order $\mathrm{TE}_{\mathrm{n} 0}$ modes was presented in [18]-[19] based on a two-dimensional arrangement of quarterwave bandstop elements of smooth profile. Like [8], this technique requires long windowed sections to achieve the matching of the filter which have a negative impact on the insertion loss of the filter and its final size. Additionally, the manufacturing by CCM is time-consuming.

Another way to accomplish the suppression of the higherorder $\mathrm{TE}_{\mathrm{n} 0}$ modes is by employing [20], where Levy introduced an inhomogeneous corrugated filter whose width is varied along the structure. More recently, this concept has been used in other high-power design methods such as [21][23]. Both methods draw on quarter-wave resonators along the propagation direction to achieve the required attenuation of the fundamental mode in the stopband. In [22], the solution is given by two concatenated filters, where one of them has a constant reduced width, and the matching requires the inclusion of two long classical tapers. Unlike [22], a singlefilter solution is proposed in [23] based on an arrangement of bandstop elements of sinusoidal profile with a smooth width variation to suppress the higher-order $\mathrm{TE}_{\mathrm{n} 0}$ modes. The higherorder non- $\mathrm{TE}_{\mathrm{n} 0}$ modes are rejected by properly adjusting the filter E-plane mechanical gap, which is not connected now to the $\mathrm{TE}_{10}$-mode response. This latter high-power technique behaves very well when a steep slope between the pass- and the rejected band is desired, although it suffers from the same problems that we have observed in [8] or [18] of cumbersome manufacturing by CCM. Recently, a high-power low-pass filter for Ka-band applications, which features low insertion loss, compact size, and stopband rejection up to the third harmonic has been also presented in [24]. The filter in [24] benefits from an easy manufacturing by CCM and all-higherorder mode suppression too. Nevertheless, none of the previous reported techniques allow power-handling levels high enough so that the multipactor testing in a multicarrier system could be avoided according, for instance, to the ESAECSS standard recommendations [5].

In this paper, in order to reach multipactor threshold levels high enough so that future tests in multicarrier systems, for instance, could be bypassed, a novel chirping technique has been applied to the length (in the propagation direction) of the step-shaped bandstop elements that compose a harmonic lowpass filter such as those in the advanced configurations of [10] and [24]. The design method is explained in Section II along with an insightful discussion on the technique's free parameters. That will aid the designer during the implementation of the high-power chirped low-pass filters. We will look, on the one hand, for size and insertion loss minimization and, on the other hand, for high-power handling capability maximization. The chirping of the length of the bandstop elements will be shown with an example for relevant specifications to increase the power handling from around 8 $\mathrm{kW}$ (non-chirped filter) to more than $100 \mathrm{~kW}$ (chirped filter). For comparison purposes, the power handled by the equivalent waffle-iron filter is only $0.15 \mathrm{~kW}$. The measured frequency response of a prototype manufactured in two halves by CCM in aluminum and then silver-plated is presented in Section III. The high-power behavior of the prototype will be also discussed in Section IV.

\section{THEORY AND DESIGN METHOD}

In [10], the possibility of achieving a low-pass filter with a very wide rejected band in the fundamental-mode frequency response was demonstrated for high-power applications. In [24], the technique of [10] was extended to get the suppression of all higher-order modes and, besides, a higher powerhandling capability compared to [10] was accomplished by means of a proper modification (tapering) of the minimum mechanical gap along the structure. Nevertheless, none of the previous filters provides a multipactor threshold level high enough to avoid, for instance, a test campaign if a multicarrier system is assumed. In this paper, chirping techniques are adequately applied during the design of the previous low-pass filters [10], [24] to dramatically improve the high-power behavior.

\section{A. Non-chirped filter}

The design of the non-chirped low-pass filter is well described in [10] for the suppression of the fundamental $\mathrm{TE}_{10}$ mode only, and in [24] if the suppression of all higher-order modes is also desired (Fig. 1). The attenuation in the required stopband for the fundamental $\mathrm{TE}_{10}$ mode is achieved by means of several $\lambda_{g} / 4$-step-shaped bandstop elements, $h$, of identical length (in the propagation direction), $l$, separated by very short waveguide sections of $l_{g a p}$ length. The $\lambda_{g} / 4$-heights of the bandstop elements of the main block of the filter are defined between the highest $\left(h_{\max }\right)$ and the shortest $\left(h_{\min }\right)$ used to reject the lowest $\left(f_{\min }\right)$ and the highest $\left(f_{\max }\right)$ frequency of the stopband, respectively. The minimum mechanical gap of the structure is a free parameter and evolves linearly from $b_{\text {gmin }}$ to $b_{\text {gmax }}$, simultaneously achieving higher-order non- $\mathrm{TE}_{\mathrm{n} 0}$ mode suppression and high-power behavior. As it is well known, the first non- $\mathrm{TE}_{\mathrm{n} 0}$ mode to appear is the $\mathrm{TE}_{01}$ mode, whose cutoff frequency, $f_{C T E O 1}$, is $c / 2 b$, being $b$ the value of the minimal mechanical gap of the filter and $c=1 / \sqrt{\varepsilon_{0} \mu_{0}}$ the speed of 
light in vacuum. Therefore, $b_{\text {gmin }}$ must be small enough in order to ensure $f_{C T E 01}>f_{\max }$ and, hence, guarantee no higherorder non- $\mathrm{TE}_{\mathrm{n} 0}$-mode propagation in the filter stopband. However, the power levels achieved are still not sufficient for some applications, as it will be demonstrated below. The matching of the filter is accomplished by means of two matching networks at the input/output ports of the main block. Finally, in order to design a filter with higher-order $\mathrm{TE}_{\mathrm{n} 0}$ mode suppression too, a smooth $x$-axis width tapering is applied to the whole device (see Fig. 1). See [10] and [24] for more details.

A novel concept has to be introduced in the non-chirped low-pass filters proposed in [10] and [24] in order to increase sufficiently the high-power handling if, for instance, the cumbersome and costly multipactor testing is to be bypassed. The concept developed in this paper would have then an enormous impact on the space filter industry.

\section{B. Chirped filter}

Some of the steps in the design of a chirped filter coincide with the design method outlined in the previous paragraph: firstly, the design of a main block which will determine the required stopband of the filter and, secondly, the design of the matching networks which will reach the input and output heights of the standard ports and the required return loss of the filter. In particular, the design begins again by fixing the $\lambda_{g} / 4$ heights of the main-block bandstop elements to achieve the required attenuation of the filter stopband (Fig. 2(a)). However, the lengths (in the propagation direction) of these elements will be now different, as will be discussed below. The steep slope between the pass- and the rejected band is accomplished through a reduced extra number, $n_{h \max }$, of bandstop elements with the largest height. The minimum

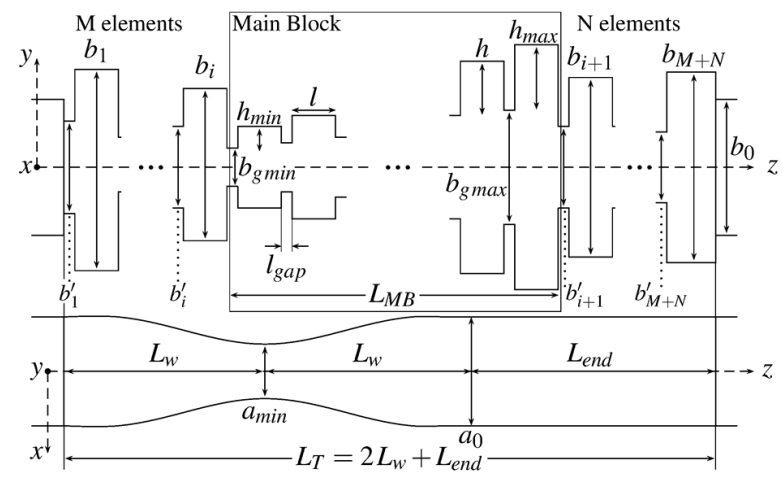

(a)

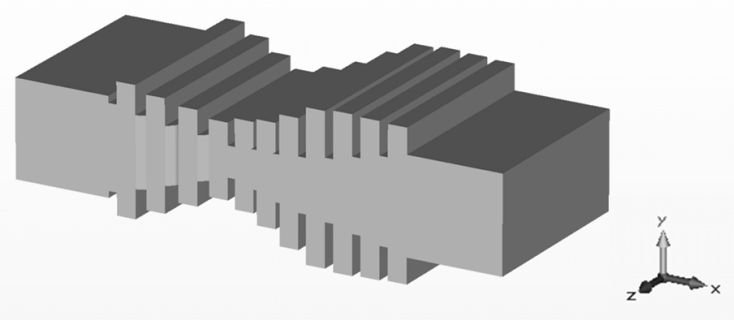

(b)

Fig. 1. Schematics of the non-chirped filter [24]: (a) main physical parameters, (b) $3 \mathrm{D}$ view of the final filter. mechanical gap, $b_{g a p}$, is defined, like in the non-chirped case, between $b_{\text {gmin }}$ and $b_{\text {gmax }}$. The matching of the filter is accomplished by means of two matching networks of $M$ and $N$ stubs (Fig. 2(b)). $M$ and $N$ are obtained by optimization (the larger $M$ and $N$, the wider the passband). Finally, a smooth width tapering is applied to suppress the higher-order $\mathrm{TE}_{\mathrm{n} 0}$ modes as it was aforementioned for the non-chirped case (Fig. 2(c)).

The main difference between chirped and non-chirped filters is that, in the chirped case, the length, $l_{i}$, of the filter step-shaped bandstop elements will be properly defined to achieve the highest power handling capability, while the frequency response is not affected. Specifically, as it will be demonstrated below, a linear chirping, following eqn. (1), of

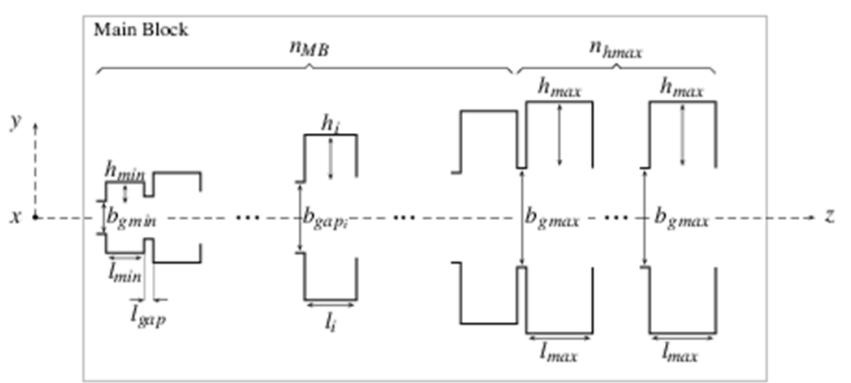

(a)
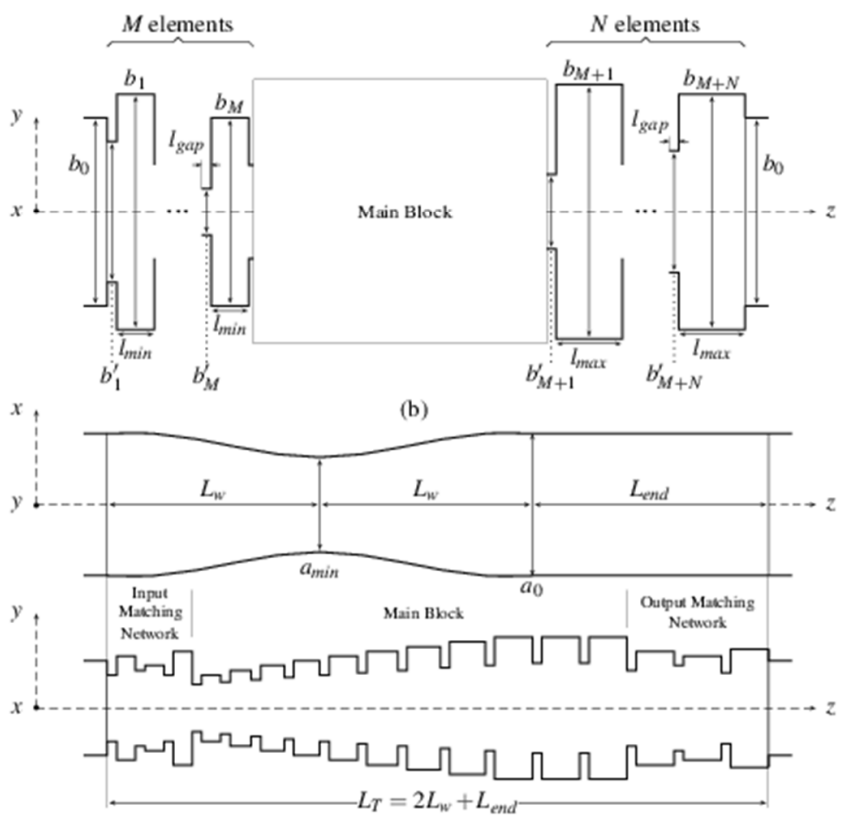

(c)

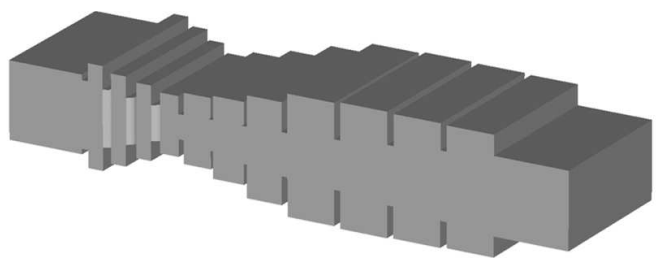

(d)

Fig. 2. Schematics of the chirped filter and its main physical parameters: (a) main block, (b) matching networks, (c) final filter profile, and (d) 3D view of the final filter. 
the length of the elements, between $l_{\min }$ and $l_{\max }$, will increase dramatically the multipactor threshold level (strictly speaking, this chirping is applied to the main-block bandstop elements only, being this length constant and equal to $l_{\min }$ or $l_{\max }$ in the stubs of the input and output matching networks).

$$
\begin{gathered}
l_{i}=\frac{l_{\max }-l_{\min }}{n_{M B}} \cdot(i-1)+l_{\min } \\
i=1,2, \ldots, n_{M B}
\end{gathered}
$$

The idea is very simple to be implemented and, in particular, it does not make the manufacturing complicated. Indeed, the relevance of this strategy can be very important since it will allow power levels so high that, for instance, the

TABLE I. FREQUENCY SPECIFICATIONS (FUNDAMENTAL MODE)

\begin{tabular}{cccc}
\multicolumn{4}{c}{ TABLE I. FREQUENCY SPECIFICATIONS (FUNDAMENTAL MODE) } \\
\hline \hline Passband & $\begin{array}{c}\text { In-band return } \\
\text { loss }\end{array}$ & Rejected band & $\begin{array}{c}\text { Out-of-band } \\
\text { attenuation }\end{array}$ \\
\hline \hline $10.7-12.7 \mathrm{GHz}$ & $>20 \mathrm{~dB}$ & $13.75-38.1 \mathrm{GHz}$ & $>60 \mathrm{~dB}$ \\
\hline \hline
\end{tabular}

TABLE II. FINAL DIMENSIONS OF THE BASELINE FILTER

\begin{tabular}{|c|c|c|c|}
\hline Matching Networks & & $=12$ & \\
\hline \multirow{3}{*}{ Main Block } & $\bar{c}_{\min }=0.4 \mathrm{~mm}$ & $h_{\max }=6.15 \mathrm{~mm}$ & $n_{\text {hmax }}=5$ \\
\hline & $b_{g \min }=3 \mathrm{~mm}$ & $b_{\operatorname{gmax}}=3 \mathrm{~mm}$ & $n_{M B}=32$ \\
\hline & $l_{\min }=1.91 \mathrm{~mm}$ & $l_{\max }=1.91 \mathrm{~mm}$ & $l_{\text {gap }}=1.91 \mathrm{~mm}$ \\
\hline Width Reduction & $a_{\min }=15 \mathrm{~mm}$ & $L_{w}=91 \mathrm{~mm}$ & $L_{\text {end }}=36 \mathrm{~mm}$ \\
\hline
\end{tabular}
(WR75 PORTS $a_{0}=19.05 \mathrm{~mm}, b_{0}=9.525 \mathrm{~mm}$ )

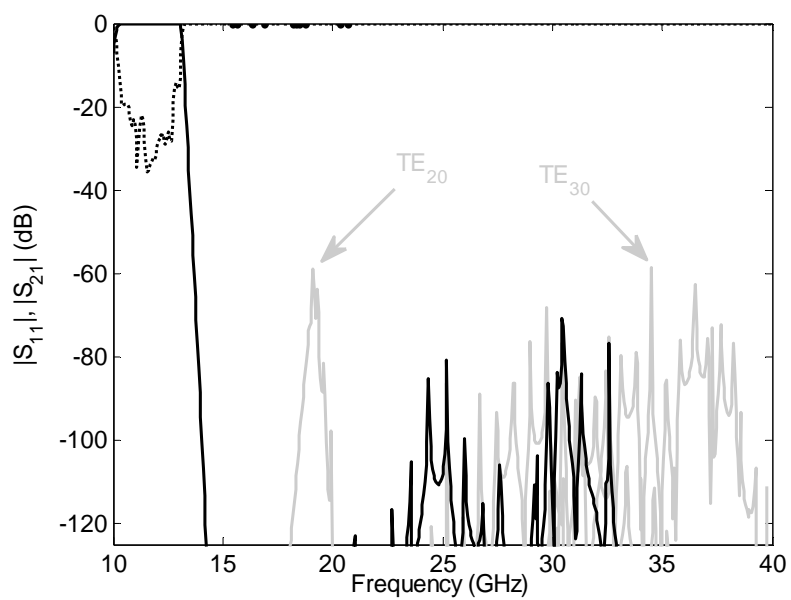

Fig. 3. FEST3D simulated frequency response $\left(\left|S_{11}\right|\right.$ in dotted line and $\left|S_{21}\right|$ in solid line) for the $\mathrm{TE}_{10}$ mode in the baseline filter with constant $3 \mathrm{~mm}$-gap (black line) and for the higher-order modes (grey lines) (rest of higher-order modes not shown are kept below $-130 \mathrm{~dB}$ ).

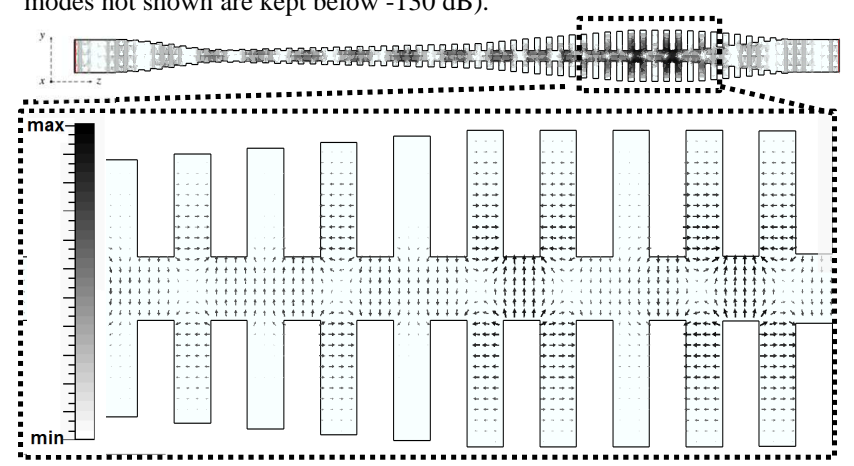

Fig. 4. E-field distribution (V/m) simulated using CST MWS at $12.7 \mathrm{GHz}$ for the baseline filter. costly multipactor testing of filters in multicarrier scenarios could be avoided. A final 3D representation of the non-chirped and chirped filters is depicted in Fig. 1(b) and Fig. 2(d), respectively.

The usefulness of the proposal in this paper is explained in this Section by means of the design of several chirped and non-chirped filters and proper comparisons. Let's begin by designing a WR75 non-chirped device fulfilling the frequency specifications defined in Table I to provide a baseline filter for the comparisons [24]. The filter achieves the suppression of the fundamental $\mathrm{TE}_{10}$ and all the higher-order $\left(\mathrm{TE}_{\mathrm{n} 0}\right.$ and non$\mathrm{TE}_{\mathrm{n} 0}$ ) modes in the stopband. For this assessment, in order to do a fair comparison with previously reported results, the total number of elements, both in the main block and in the matching networks, has been intentionally fixed identical in this step-shaped filter as in [23] (sinusoidal stubs). Besides, in this baseline filter, $l$ and $l_{\text {gap }}$ have been set both equal to $1.91 \mathrm{~mm}$, and the E-plane mechanical gap has been fixed constant and equal to $3 \mathrm{~mm}$ as in [23] too. This choice of values does not still take full advantage of the benefits of the presence of free parameters in the technique. However, the frequency response of this device and the filter designed following [23] coincide. The final main dimensions of the filter are shown in Table II and its simulated frequency response in Fig. 3, showing that the required specifications are fulfilled.

In order to analyze the high-power behavior of the filter, we have studied the multipactor phenomenon, which can cause the breakdown due to high EM fields in vacuum conditions in space applications [25]. Aiming at enhancing the high-power behavior of the filter, it is indispensable to know accurately the EM field distribution inside the device. The maximum EM fields of the step-shaped filter are obtained at $12.7 \mathrm{GHz}$, which is the upper passband edge frequency. As can be seen in Fig. 4, this kind of filters shows a quite interesting field distribution. The maximum fields are placed in the highest step-shaped bandstop elements region. Specifically, as is illustrated in Fig. 4, two different field directions can be observed, which will affect to the free-electron trajectories and, therefore, to the multipactor threshold. The first one is the field component (mainly in the $y$-direction) placed in the waveguide section between two bandstop elements, and the second one is the field component (mainly in the $z$-direction) placed inside the bandstop elements. Therefore, enhancing both critical sections should provide better high-power behavior. As a first approach, if we want to reduce the probability of the multipactor phenomenon, the well-reported solution is to enlarge the E-plane mechanical gap [26] by means of larger values of $b_{\text {gap }}$. This is very easy in our case, since $b_{\text {gap }}$ is, actually, a free parameter. However, this will only lead to a limited improvement (see Section II.B.1 below). The avoidance of the multipactor between the bandstopelement walls will be then carefully studied (Section II.B.3).

1) Influence of the E-plane Mechanical Gap, $b_{\text {gap }}$

When the higher-order non- $\mathrm{TE}_{\mathrm{n} 0}$ mode suppression is a requirement, it is necessary to guarantee that the mode with 
the lowest cutoff frequency ( $\mathrm{TE}_{01}$ mode in our example) is not able to propagate in the section with minimum E-plane mechanical gap, $b_{\text {gmin }}$. In fact, as it has been demonstrated in Fig. 3, with an E-plane mechanical gap equal to $3 \mathrm{~mm}$, the $\mathrm{TE}_{01}$-mode cutoff frequency is shifted above the third harmonic for a filter fulfilling the specifications defined in Table I for the fundamental mode.

On the other hand, as pointed out earlier, the maximum EM fields at the critical frequency are placed in the region of the highest step-shaped bandstop elements. If the high-power behavior of the filter is required to be increased, a larger gap, $b_{\text {gmax }}$, can be adjusted between the highest bandstop elements. Therefore, higher-order non $\mathrm{TE}_{\mathrm{n} 0}$-mode suppression and highpower behavior can be achieved simultaneously if a linear variation of the E-plane mechanical gap is performed between $b_{\text {gmin }}$ and $b_{\text {gmax }}$. Additionally, this will be also advantageous in terms of insertion loss, compared to a structure with a constant mechanical gap, $b_{\text {gmin }}$, [24], [28].

For the specifications defined in Table I, three step-shaped filters have been also designed using a WR75 port standard. The only difference between them and the baseline filter (constant $3 \mathrm{~mm}$-gap) is the applied linear variation of the Eplane mechanical gap (see Fig. 2(a)) between $b_{\text {gmin }}=3$ and $b_{\text {gmax }}=4,5$, and $6 \mathrm{~mm}$. As it is depicted in Fig. 5, all filters show an excellent attenuation level and in-band return loss, demonstrating that the E-plane minimum mechanical gap can be changed without altering the frequency response. Additionally, as it has been said, this minimum mechanical gap increase along the propagation direction ( $z$-axis) produces a slight improvement in the insertion loss of the filter. For instance, the baseline constant 3-mm-gap filter shows an inband insertion loss better than $0.25 \mathrm{~dB}$, while the in-band insertion loss of the filter with a gap variation between 3 to $6 \mathrm{~mm}$ is kept below $0.22 \mathrm{~dB}$. Moreover, as expected, the highpower simulations of the filters show that the multipactor power threshold level increases with the size of the E-plane mechanical gap (see Table III). It is important to note that, in opposition to the baseline filter, the EM field distribution mainly oscillates now between the bandstop element walls in the propagation direction (z-axis) and becomes quite weaker in the waveguide between the bandstop elements, see Fig. 6(a) and Fig. 6(b). Nevertheless, these values of multipactor thresholds are not sufficient if multipactor tests need to be avoided for instance in multicarrier scenarios and, thus, an alternative approach has to be sought.

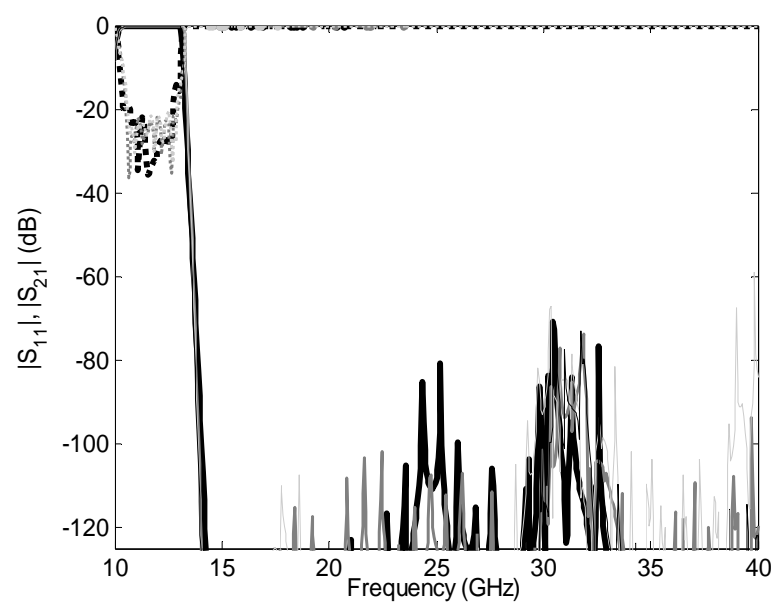

Fig. 5. FEST3D simulated frequency response $\left(\left|S_{11}\right|\right.$ in dotted line and $\left|S_{21}\right|$ in solid line) for the $\mathrm{TE}_{10}$ mode in the step-shaped filter with: constant $3 \mathrm{~mm}$-gap (thick black line), gap variation between $3-4 \mathrm{~mm}$ (thin black line), gap variation between $3-5 \mathrm{~mm}$ (thick grey line) and gap variation between $3-$ $6 \mathrm{~mm}$ (thin grey line).

TABLE III. COMPARISON OF THE HIGH-POWER BEHAVIOR OF THE FILTERS WITH DIFFERENT GAP VARIATION

\begin{tabular}{cc}
\hline \hline E-plane mechanical gap & $\begin{array}{c}\text { Power threshold (kW) } \\
\text { (SPARK3D) }\end{array}$ \\
\hline Smooth profile filter (designed following [23]) & 7.5 \\
Constant 3mm-gap (baseline filter) & 5.5 \\
Gap variation between 3-4 mm & 6.6 \\
Gap variation between 3-5 mm & 7.0 \\
Gap variation between 3-6 mm & 8.0 \\
\hline \hline
\end{tabular}
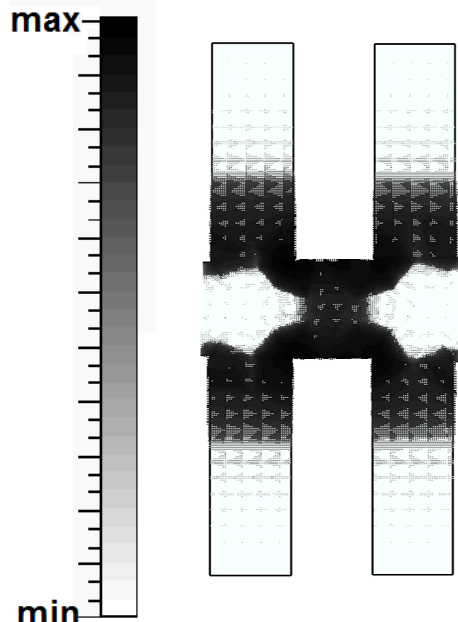

(a)

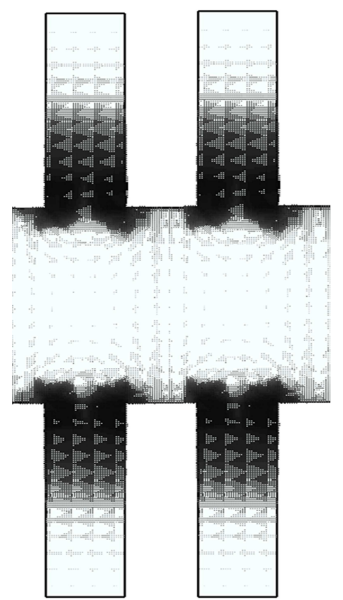

(b)

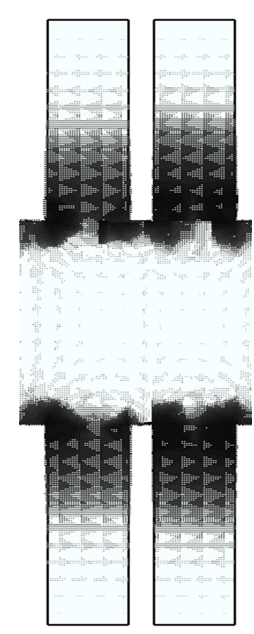

(c)

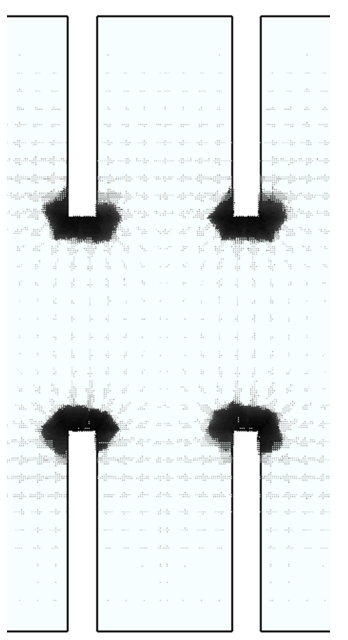

(d)

Fig. 6. E-field distribution (V/m) in the highest bandstop elements area, simulated with CST MWS at 12.7 GHz for the step-shaped filter with: (a) constant 3 $\mathrm{mm}$-gap, $l_{\text {gap }}=1.91 \mathrm{~mm}$ and $l=1.91 \mathrm{~mm}$, (b) gap variation between $3-6 \mathrm{~mm}, l_{\text {gap }}=1.91 \mathrm{~mm}$ and $l=1.91 \mathrm{~mm}$, (c) gap variation between $3-6 \mathrm{~mm}$, $l_{\text {gap }}=0.825 \mathrm{~mm}$ and $l=1.91 \mathrm{~mm}$, and (d) gap variation between $3-6 \mathrm{~mm}, l_{\text {gap }}=0.825 \mathrm{~mm}$ and $l=3.82 \mathrm{~mm}$. 
2) Influence of the Waveguide Length between the Bandstop Elements, $l_{\text {gap }}$

As it is well known and it has been extensively studied in the literature [27], [29], the multipactor discharge threshold increases when the length of the iris is decreased. This is translated, in the novel filters proposed in this paper, into a reduction of the waveguide length between the bandstop elements or $l_{\text {gap }}$. Moreover, this reduction yields to more compact structures. In fact, the waveguide length between the bandstop elements is shown with an example below to have no negative influence on the $\mathrm{TE}_{10}$-mode frequency response of the step-shaped filter and, actually, it could be ideally reduced to zero although, in practice, it must have a value which will be determined by the fabrication constrains. In our case, the minimum value of $l_{\text {gap }}$ is fixed to $0.825 \mathrm{~mm}$ since this is the minimum value that our fabrication facilities permit (to obtain a stiff device using $\mathrm{CCM}$ ).

If we consider a novel filter identical to that in Section II.B. 1 with gap variation between 3 to $6 \mathrm{~mm}$, but now with $l_{\text {gap }}$ equal to $0.825 \mathrm{~mm}$ instead of $1.91 \mathrm{~mm}$, the specifications in Table I are perfectly fulfilled as can be seen in Fig. 7. The total length of the filter $L_{T}$ is equal to $156 \mathrm{~mm}$, which implies a reduction of $25 \%$ in size. Moreover, this filter shows a slight improvement in the insertion loss $(0.21 \mathrm{~dB})$. However, the power handling capability is not improved as much as we initially could have guessed though $\left(P_{t h r}=8.2 \mathrm{~kW}\right)$. This is due to the fact that the maximum EM field component oscillates mainly between the waveguide walls of the bandstop elements in the propagation direction (z-axis), as can be observed in Fig. 6(c). This leads us to the conclusion, already mentioned before, that, if a higher power-handling capability is desired, chirping techniques should be applied to the bandstop elements length, $l$. With a larger $l$ in the critical region, multipactor can be prevented between the bandstop element walls.

\section{3) Influence of the Bandstop Elements Length, $l$.}

As it was shown previously, if the E-plane mechanical gap is large enough, the EM field distribution between the walls of the bandstop elements in the propagation direction ( $z$-axis) is the most significant component for the estimation of the multipactor threshold. Hence, the bandstop element length should be fixed appropriately if a higher-power behavior is necessary. Indeed, $l$ could be increased without negatively affecting the frequency response, as shown below.

In order to dissect the most appropriate $l$ values, four stepshaped filters have been considered with the same parameters as the example proposed in Section II.B.2 (E-plane mechanical gap variation between 3 and $6 \mathrm{~mm}$ and $l_{\text {gap }}$ equal to $0.825 \mathrm{~mm})$ with different constant values of $l(l=2.39$, 2.87, 3.35, and $3.82 \mathrm{~mm}$ ). As it is demonstrated in Fig. 8 as an example, the filter with largest $l$ fulfills perfectly the frequency specifications defined in Table I. Moreover, as can be observed in Table IV, the multipactor threshold is dramatically increased in the critical area (see also Fig. 6(d)), making it high enough to reach power levels which could avoid, for instance, future multipactor tests in multicarrier systems. In a practical case, in order to design a filter with the highest power-handling capability and, at the same time, the

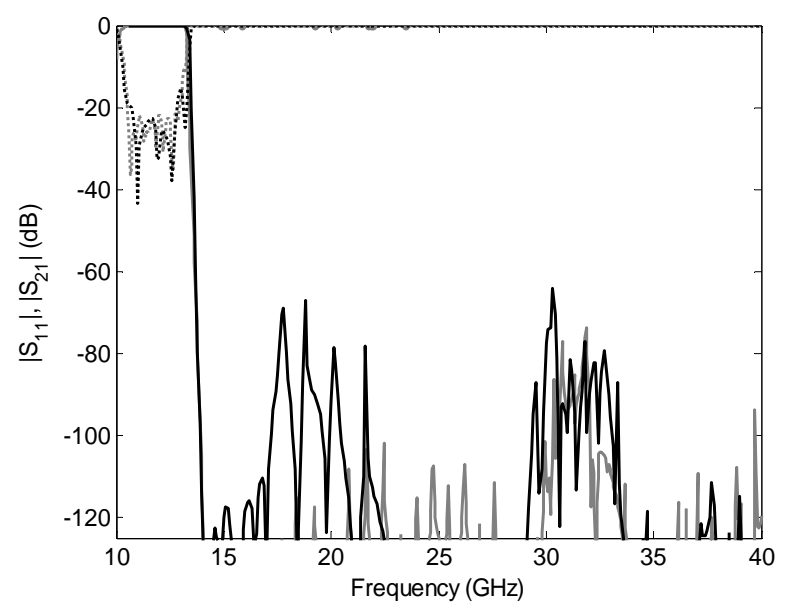

Fig. 7. FEST3D simulated frequency response $\left(\left|S_{11}\right|\right.$ in dotted line and $\left|S_{21}\right|$ in solid line) for the $\mathrm{TE}_{10}$ mode in the step-shaped filter with gap variation between $3-6 \mathrm{~mm}$ and: $l_{\text {gap }}=1.91 \mathrm{~mm}$ (grey line) or $l_{g a p}=0.825 \mathrm{~mm}$ (black line).

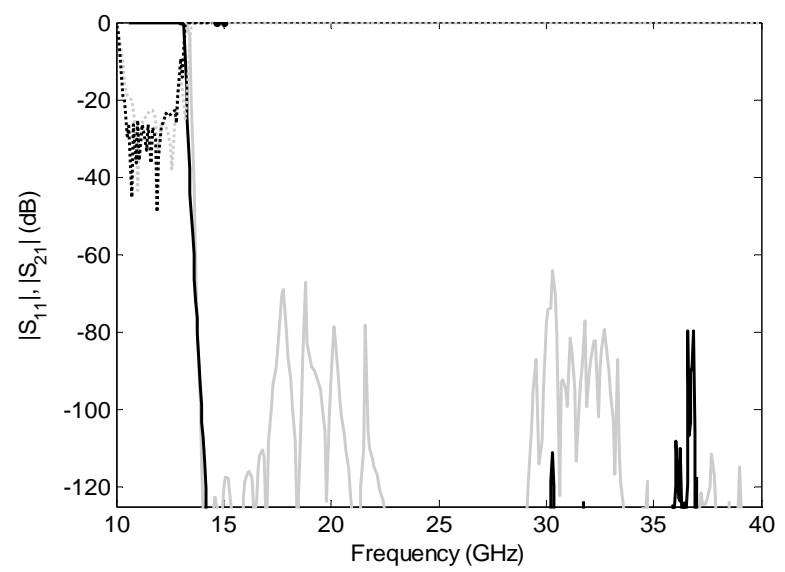

Fig. 8. FEST3D simulated frequency response $\left(\left|S_{11}\right|\right.$ in dotted line and $\left|S_{21}\right|$ in solid line) for the $\mathrm{TE}_{10}$ mode in the step-shaped filter with: gap variation between $3-6 \mathrm{~mm}, l_{\text {gap }}=0.825 \mathrm{~mm}$ and: $l=1.91 \mathrm{~mm}$ (grey line) or $l=3.82 \mathrm{~mm}$ (black line).

TABLE IV. COMPARISON OF THE HIGH-POWER BEHAVIOR OF THE FILTERS WITH DIFFERENT BANDSTOP ELEMENT LENGTHS

\begin{tabular}{cc}
\hline \hline$l(\mathrm{~mm})$ & Power threshold $(\mathrm{kW})($ SPARK3D) \\
\hline \hline $1.91($ Section II.B.2) & 8.2 \\
2.39 & 11.8 \\
2.87 & 16 \\
3.35 & $>100$ \\
3.82 & $>100$ \\
\hline \hline
\end{tabular}

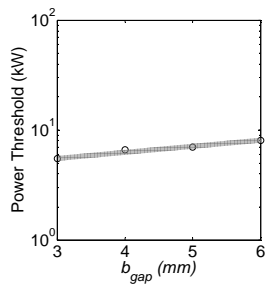

(a)

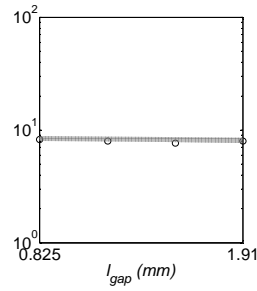

(b)

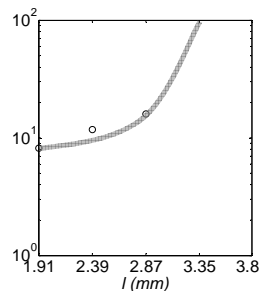

(c)
Fig. 9. Summary of the power threshold levels obtained in Section II as a function of: (a) $b_{g a p}$, (b) $l_{g a p}$, and (c) $l$. 
minimum total length, the length of the bandstop elements will not be constant but linearly chirped between $l_{\min }$ and $l_{\max }$, following eqn. (1), as in the example of Section III. $l_{\min }$ is the length of the $h_{\min }$-height bandstop element and $l_{\max }$ is the length of the $h_{\max }$-height element in the critical region.

The main conclusions of the discussions in Sections II.B.1, 2 , and 3 above are summarized in Fig. 9, showing the influence of the gap width, $b_{\text {gap }}$, the distance between bandstop elements, $l_{\text {gap }}$, and the length of the bandstop elements, $l$, on the filter multipactor threshold level ( $y$-axis in logarithmic scale), for the same frequency behavior.

\section{DESIGN EXAMPLE: Simulation AND MEASUREMENT}

As a design example, a novel multipactor-free low-loss harmonic waveguide low-pass filter with the fundamental $\mathrm{TE}_{10}$ mode as well as all higher-order modes suppressed in the

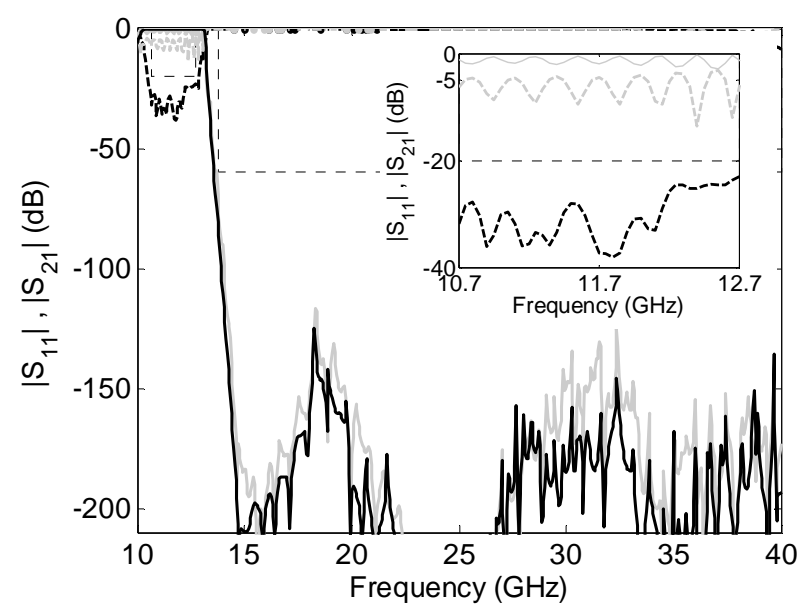

Fig. 10. FEST3D simulated frequency response for the $\mathrm{TE}_{10}$ mode in the main block of the novel filter (grey line) and including the matching networks (black line): $\left|S_{11}\right|$ in dotted line and $\left|S_{21}\right|$ in solid line. Specifications in dashed line. Inset: detail of the passband.

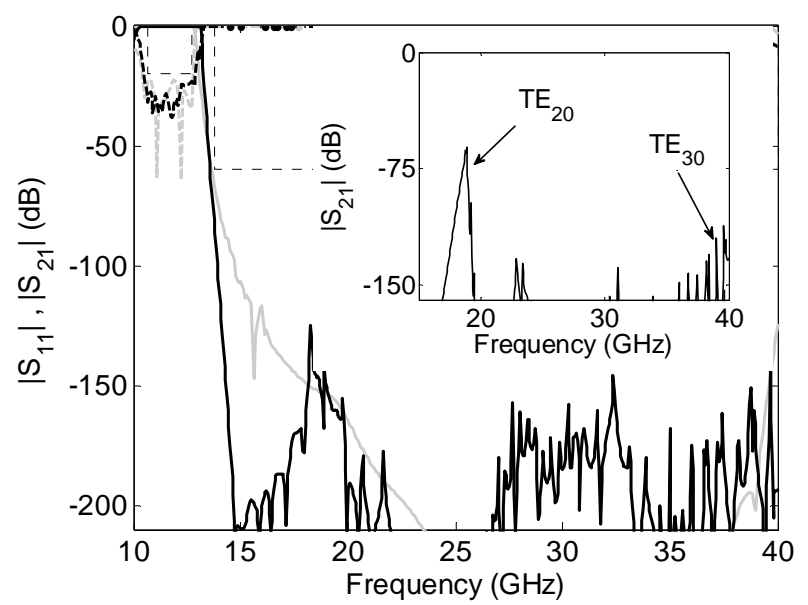

Fig. 11. FEST3D simulated frequency response for the $\mathrm{TE}_{10}$ mode in the novel filter (black line) and the waffle-iron filter (grey line): $\left|S_{11}\right|$ in dotted line and $\left|S_{21}\right|$ in solid line. Specifications in dashed line. Inset: higher-order mode suppression (novel filter). Modes not shown are below $-160 \mathrm{~dB}$. stopband, following the procedure in Section II, has been designed, manufactured, and characterized, fulfilling the frequency specifications given in Table I. In the filter, a linear chirping technique has been applied to the length of the stepshaped bandstop elements so that cumbersome and costly multipactor tests in multicarrier systems could be avoided.

The heights of the largest and shortest bandstop elements have been set to $\lambda_{g} / 4$ at the minimum and maximum stopband frequency, respectively, and further refined with a few simulations using FEST3D. Their final values are $h_{\text {max }}=5.88 \mathrm{~mm}$ and $h_{\text {min }}=0.5 \mathrm{~mm}$. Moreover, the steep slope between the pass- and the rejected-band is easily achieved with $n_{\text {hmax }}=5$. The E-plane mechanical gap is linearly defined between $b_{\text {gmin }}=3 \mathrm{~mm}$ and $b_{\text {gmax }}=6 \mathrm{~mm}$, since this allows high power operation, low insertion loss, and higher-order non$\mathrm{TE}_{\mathrm{n} 0}$ modes suppression simultaneously. $l_{\text {gap }}$ is $0.825 \mathrm{~mm}$, since this is the minimum separation between bandstop elements that our available fabrication facilities permit. A linear chirp has been defined, following eqn. (1), between $l_{\text {min }}$ and $l_{\max }$ which are fixed to $1.91 \mathrm{~mm}$ and $3.26 \mathrm{~mm}$, respectively. Once the main block parameters have been set (see Table V), we simulate its frequency behavior. As can be observed in Fig. 10 (grey line), the required attenuation level in the stopband of filter is achieved. However, the return loss of the main block alone does not fulfil the frequency requirements.

Therefore, once the main block filter is designed and the required stopband of the filter is achieved, the next step is the design of the matching networks to get the required pass-band return loss and to reach the standard port dimensions. $M=7$ and $N=2$ stubs have been added at the input and output, respectively. Then, an optimization process is run over the elements of the matching networks using the FEST3D optimizer module, and the final heights $b_{i}$ and $b_{i}^{\prime}$ are given in Table VI (the difference between the return loss obtained with only the main block and with the main block and the matching networks is shown in Fig. 10-inset-). As it can be clearly seen in Fig. 10, the return loss is adjusted as required by the introduction of the matching networks, while the stopband rejection remains almost unaltered.

Finally, a width reduction with a Hanning window between $a_{0}$ and $a_{\min }=14.85 \mathrm{~mm}$ along $L_{w}=65.5 \mathrm{~mm}$, is introduced to guarantee the $\mathrm{TE}_{\mathrm{n} 0}$-mode suppression $\left(L_{\text {end }}=79.15 \mathrm{~mm}\right.$ ).

The simulated frequency response of the final filter is depicted again in Fig. 11 along with the frequency response of a classical waffle-iron filter designed to fulfil the same frequency specifications, following [13]. For both filters, the

TABLE V. FINAL Dimensions OF THE DESIGN EXAMPLE (WR75 PORTS $a_{0}=19.05 \mathrm{~mm}, b_{0}=9.525 \mathrm{~mm}$ )

\begin{tabular}{|c|c|c|c|}
\hline Matching Networks & \multicolumn{3}{|c|}{$M=7$} \\
\hline \multirow{3}{*}{ Main Block } & $h_{\min }=0.5 \mathrm{~mm}$ & $h_{\max }=5.88 \mathrm{~mm}$ & $n_{\text {hmax }}=5$ \\
\hline & $b_{g \min }=3 \mathrm{~mm}$ & $b_{g \max }=6 \mathrm{~mm}$ & $n_{M B}=48$ \\
\hline & $l_{\min }=1.91 \mathrm{~mm}$ & $l_{\max }=3.26 \mathrm{~mm}$ & $l_{g a p}=0.825 \mathrm{~mm}$ \\
\hline "Width Reduction & $a_{\min }=14.85 \mathrm{~mm}$ & $\bar{L}_{w}=65.5 \mathrm{~mm}$ & $L_{\text {end }}=79.15 \mathrm{~mm}$ \\
\hline
\end{tabular}

TABLE VI. OPTIMIZED (FINAL) HeIGTS OF THE STUBS IN THE MATCHING NETWORKS FOR THE EXAMPLE IN SECTION III (mm)

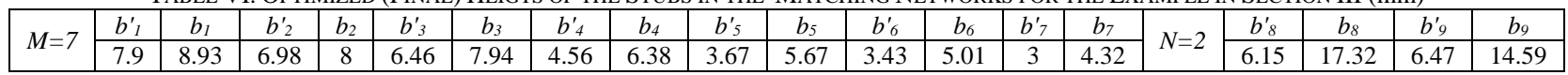




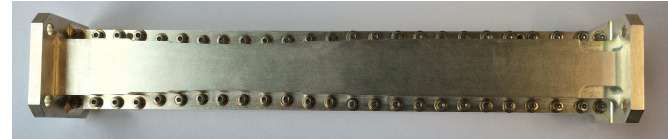

Fig. 12. Photograph of the prototype (assembled).

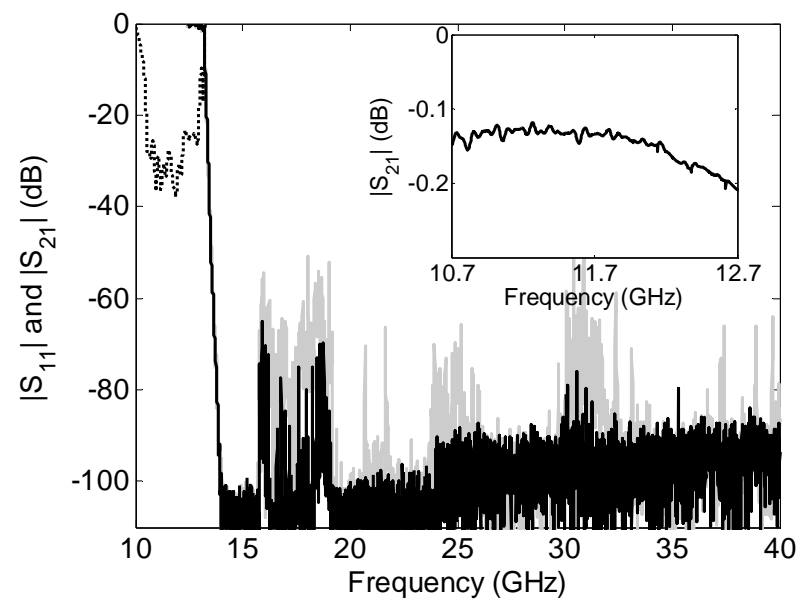

Fig. 13. Measurements of the novel filter with all higher-order mode suppression: $\left|S_{11}\right|$ (black dashed line) and $\left|S_{21}\right|$ (black solid line) of the $\mathrm{TE}_{10}$ mode; $\left|S_{21}\right|$ of the $\mathrm{TE}_{10}$ mode with $90^{\circ} \mathrm{H}$-plane bends in the measurement setup (grey line). Inset: detail of the insertion loss.

in-band return loss is better than $20 \mathrm{~dB}$ and the attenuation level in the stopband is kept below $60 \mathrm{~dB}$. All higher-order modes are perfectly suppressed as it is shown in Fig. 11 inset- for the novel filter. However, compared to the classical waffle-iron filter and [23], the novel filter shows an improved insertion loss $(0.22$ vs $0.26 \mathrm{~dB}$ and 0.22 vs $0.3 \mathrm{~dB}$, respectively, using the conductivity of silver) and, more importantly, much higher power handling capability as will be demonstrated in Section IV.

A prototype of the novel filter has been manufactured in two halves by CCM (machining radius $r=0.75 \mathrm{~mm}$ ) in bare aluminum and then silver-plated (Fig. 12). The measurements of the device were carried out using an Agilent 8722 VNA, proper waveguide-to-coaxial transitions, waveguide tapers, and calibration kits. The measurements show an attenuation larger than $60 \mathrm{~dB}$ up to $40 \mathrm{GHz}$ and the in-band return loss is kept better than $20 \mathrm{~dB}$ in the passband (see Fig. 13). The worst value of the insertion loss of the filter is $0.21 \mathrm{~dB}$ (Fig. 13 inset-). Higher-order mode suppression was checked by introducing bends and misalignments at the filter input and output ports [11]. For instance, $90^{\circ} \mathrm{H}$-plane bends were used to observe the higher-order $\mathrm{TE}_{\mathrm{n} 0}$-mode filter behavior (Fig. 13, grey line). As predicted, the filter features an excellent higherorder mode suppression. Last but not least, the novel chirped filters can be easily manufactured by CCM.

\section{High-POWER ANALYSIS}

The high-power behavior of the novel chirped filter designed in Section III and the classical waffle-iron filter for the same frequency specifications has been estimated by means of SPARK3D, considering the EM fields previously calculated with CST MWS. The simulations have been done at $12.7 \mathrm{GHz}$ (upper passband edge) which is the frequency where the EM fields are maximum and the multipactor threshold will be minimum, using silver as background material.

As it has been aforementioned and well discussed in Section II, the maximum EM fields are placed in the region where the highest bandstop elements are located. The filter gap in this area has been made so large $(6 \mathrm{~mm})$ and the length of the highest bandstop elements is also so large $(3.26 \mathrm{~mm})$ that the EM field is very weak in this region and, therefore, a very high power handing capability is possible. In fact, the multipactor threshold power levels obtained in this example are better than $100 \mathrm{~kW}$ (vs. only $0.15 \mathrm{~kW}$ in the classical waffle-iron filter and $7.5 \mathrm{~kW}$ in the filter designed following [23]). Therefore, this filter could be used to avoid a multipactor test in a multicarrier system with, for example, 12 carriers of $120 \mathrm{~W}$ each (equivalent multicarrier peak power equal to $17.3 \mathrm{~kW}$ ), since it handles power levels larger than $70 \mathrm{~kW}$ in analysis ( $6 \mathrm{~dB}$ above the peak power), meeting the safety margins prescribed by the ECCS-ESA document on high-power testing [5].

\section{CONCLUSION}

In this paper, a very simple-to-use chirping technique has been applied to the design of high-power compact low-loss waveguide harmonic low-pass filters with all higher-order modes suppressed in the stopband. This proposal has been shown to avoid, for instance, cumbersome multipactor testing campaigns in multicarrier systems. The main characteristic of this method is that the multipactor threshold of the filter can be freely adjusted as high as the application requires. In particular, the multipactor threshold has been shown to increase from around $8 \mathrm{~kW}$ (non-chirped case) to more than $100 \mathrm{~kW}$ (chirped case) in our example, simply by using this chirping strategy. Moreover, the filter can be easily manufactured by conventional machining methods such as CCM. Compared to a classical waffle-iron filter for the same frequency specifications, the novel device benefits from a better insertion loss and a multipactor-free operation: more than $100 \mathrm{~kW}$ for our filter vs. only $0.15 \mathrm{~kW}$ for the waffle-iron case. Such high multipactor thresholds have never been reported for such kind of filters. A prototype has been manufactured in silver-plated aluminum and its frequency behavior has been measured and compared with the simulations showing a remarkable accordance.

\section{ACKNOWLEDGMENT}

The authors would like to thank the help of NOVALTI S.A. with the fabrication of the prototypes.

\section{REFERENCES}

[1] R. Levy, R. Snyder, and G. Matthaei, "Design of microwave filters," IEEE Trans. Microw. Theory. Techn., vol. 50, no. 3, pp. 783-793, Mar. 2002.

[2] I. Hunter, L. Billonet, B. Jarry, and P. Guillon, "Microwave filters, applications and technology," IEEE Trans. Microw. Theory. Techn., vol. 50, no. 3, pp. 794-805, Mar. 2002.

[3] V. Boria and B. Gimeno, "Waveguide filters for satellites," IEEE Microwave Magazine, vol. 8, no. 5, pp. 60-70, Oct. 2007.

[4] P. Sarasa, A. Gonzalez, H. Esteban, P. Mader, K. Tossou, P. Lepeltier, "Comparative study of the power handling capability of space broadband antenna filters in ku-band," in Proc. $5^{\text {th }}$ International Workshop on Multipactor, Corona and Passive Intermodulation in 
Space RF Hardware (MULCOPIM 2005), pp. 93-99, ESA-ESTEC, Noordwijk, The Netherlands, 2005.

[5] ESA-ESTEC, Space Engineering: Multipacting, Design and Test, vol. ECSS-20-01A, edited by ESA Publication Division, the Netherlands.

[6] S. Anza, C. Vicente, J. Gil, M. Mattes, D. Wolk, U. Wochner, V. E. Boria, B. Gimeno, and D. Raboso, "Prediction of Multipactor Breakdown for Multicarrier Applications: The Quasi-Stationary Method," IEEE Trans. Microw. Theory. Techn., vol. 60, no. 7, pp. 2093 2105, Jul. 2012

[7] R. J. Cameron, C. M. Kudsia, and R. R. Mansour, Microwave Filters for Communication Systems: Fundamentals, Design and Applications. Hoboken, NJ: John Wiley \& Sons, 2007.

[8] I. Arregui, I. Arnedo, A. Lujambio, M. Chudzik, D. Benito, R. Jost, F. J. Görtz, T. Lopetegi, and M. A. G. Laso, "A compact design of highpower spurious-free low-pass waveguide filters," IEEE Microw. Wireless Compon. Lett., vol. 20, no. 11, pp. 595-597, Nov. 2010.

[9] V. Semenov, J. Rasch, E. Rakova, and J. Johansson, "General study of multipactor between curved metal surfaces," IEEE Trans. Plasma Sci. vol. 42, no. 3, pp. 721-728, Mar. 2014.

[10] F. Teberio, I. Arregui, A. Gomez-Torrent, E. Menargues, I. Arnedo, M. Chudzik, M. Zedler, F. -J. Görtz, R. Jost, T. Lopetegi, and M. A. G Laso, "Low-loss compact Ku-band waveguide low-pass filter," IEEE $M T T-S$, Phoenix, May 2015.

[11] K. L. Wu and G. McDonald, "Coping with hidden spurious harmonic modes in the design of low pass corrugated waveguide filters," Microwave Journal, vol. 44, no. 11, pp. 180-183, Nov. 2001.

[12] R. Levy, "Tapered corrugated waveguide low-pass filters," IEEE Trans. Microw. Theory Techn., vol. 21, no. 8, pp. 526-532, Aug. 1973.

[13] G. L. Matthaei, L. Young, and E. M. T. Jones, Microwave Filters, Impedance-Matching Networks, and Coupling Structures. Norwood: Artech House, 1980.

[14] H. F. Chapelle, "Waveguide low-pass filters using evanescent mode inductors," Microwave Journal, vol. 2A, no. 12, pp. 71-72, December 1978.

[15] L. Young and B. M. Schiffman, "New and improved types of waffle-iron filters," Proceedings of the Institution of Electrical Engineers, vol. 110 no. 7, pp. 1191-1198, July 1963.

[16] E. Sharp, "A high-power wide-band waffle-iron filter," IEEE Trans. Microw. Theory. Techn., vol. 11, no. 2, pp. 111-116, Mar 1963.

[17] R. Bunger and F. Arndt, "Gsm/moment-method cad of waffle-iron filters with round teeth," IEEE MTT-S, vol. 4, pp. 1691-1694, 1999.

[18] I. Arregui, F. Teberio, I. Arnedo, A. Lujambio, M. Chudzik, D. Benito, R. Jost, F.-J. Görtz, T. Lopetegi, and M. Laso, "High-power low-pass harmonic waveguide filter with TEn0-mode suppression," IEEE Microw. Wireless Compon. Lett., vol. 22, no. 7, pp. 339-341, July 2012.

[19] F. Teberio, I. Arregui, I. Arnedo, M. Chudzik, R. Jost, F.-J. Görtz, T. Lopetegi, and M. A. G. Laso, "Tailoring of higher-order mode suppression in a high-power alternative to classical waffle-iron filters," Microw. Opt. Technol. Lett., vol. 56, no. 12, pp. 2967-2974, Dec. 2014.

[20] R. Levy, "Inhomogeneous stepped-impedance corrugated waveguide low-pass filters," IEEE MTT-S, Long Beach, 2005, pp. 123-126.

[21] I. Arregui, F. Teberio, I. Arnedo, A. Lujambio, M. Chudzik, D. Benito, T.Lopetegi,R.Jost,F.-J.Görtz,J.Gil,C.Vicente,B.Gimeno,V. E. Boria, D Raboso, and M. A. G. Laso, "Multipactor-resistant low-pass harmonic filters with wide-band higher-order mode suppression," presented at the IEEE Int. Microw. Symp. Digest, Seattle, WA, USA, Jun. 2013.

[22] F. De Paolis, R. Goulouev, J. Zheng, and M. Yu, "Cad procedure for high-performance composite corrugated filters," IEEE Trans. Microw. Theory. Techn., vol. 61, no. 9, pp. 3216-3224, Sept. 2013.

[23] I. Arregui, F. Teberio, I. Arnedo, A. Lujambio, M. Chudzik, D. Benito, T. Lopetegi, R. Jost, F.-J. Görtz, J. Gil, C. Vicente, B. Gimeno, V.E. Boria, D. Raboso, and M.A.G. Laso, "High-power low-pass harmonic filters with higher-order $\mathrm{TE}_{\mathrm{n} 0}$ and non- $\mathrm{TE}_{\mathrm{n} 0}$ mode suppression: Design method and multipactor characterization," IEEE Trans. Microw. Theory Techn., vol. 61, no. 12, pp. 4376-4386, Dec. 2013.

[24] F. Teberio, I. Arregui, A. Gomez-Torrent, E. Menargues, I. Arnedo, M. Chudzik, M. Zedler, F. -J. Görtz, R. Jost, T. Lopetegi, and M. A. G Laso, "High-power waveguide low-pass filter with all-higher-order mode suppression over a wide-band for Ka-band satellite applications," IEEE Microw. Wireless Compon. Lett., vol. 25, no. 8, pp. 511-513, Aug. 2015.

[25] J. Vaughan, "Multipactor," IEEE Trans. on Electron Devices, vol. 35, no. 7, pp. 1172-1180, Jul. 1988.

[26] C. Kudsia, R. Cameron, and W.-C. Cheug, "Innovations in microwave filters and multiplexing networks for communications satellite systems,"
IEEE Trans. Microw. Theory Techn., vol. 40, no. 6, pp. 1133-1148, Jun. 1992.

[27] R. Udiljak, D. Anderson, M. Lisak, J. Puech, and V. Semenov, "Multipactor in a waveguide iris," IEEE Trans. Plasma Sci., vol. 35, no. 2, pp. 388-395, Apr. 2007.

[28] D. M. Pozar, Microwave Engineering. Hoboken: John Wiley \& Sons, 2005.

[29] D. Wolk, C. Vicente, H. L. Hartnagel, M. Mattes, J. R. Mosig, and D. Raboso, "An investigation of the effect of fringing fields on multipactor breakdown," in Proc. $5^{\text {th }}$ International Workshop on Multipactor, Corona and Passive Intermodulation in Space RF Hardware (MULCOPIM 2005), p. 93-99, ESA-ESTEC, Noordwijk, The Netherlands, 2005.

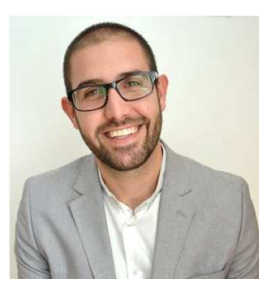

Fernando Teberio received the Telecommunication Engineering degree and the M.Sc. degree from the Public University of Navarre, Spain, in 2009 and 2011, respectively. He has collaborated in research projects supported by the Spanish Government and the European Space Agency (ESA). He is currently working towards the $\mathrm{Ph}$. D. degree at the Electrical and Electronic Engineering Department of the Public University of Navarre. His research interests include periodic structure devices and design of passive components for communications satellites for microwave and millimetre wave frequency ranges.

Mr. Teberio is the recipient of a Network Partnering Initiative (NPI) grant from the European Space Agency (ESA) to support his doctoral research.

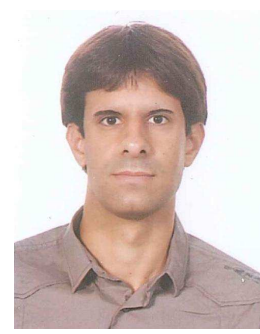

Ivan Arregui (S'08-M'12) received the Telecommunication Engineering, M.Sc. and the Ph.D degree from the Public University of Navarre, Spain, in 2005, 2008, and 2013, respectively. He is currently an Assistant Professor in the Electrical and Electronic Engineering Department of the Public University of Navarre. His research interests include periodic structure devices for microwave, millimeter wave and terahertz frequency ranges, numerical techniques for the inverse scattering synthesis, and design of passive components for communications

satellites.

Dr. Arregui was the recipient of a grant from the Spanish Ministry of Science and Innovation and is cofounder of the spin-off company TAFCO Metawireless.

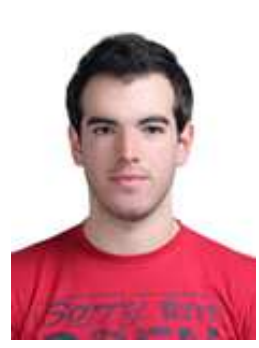

Adrian Gomez-Torrent was born in Pamplona (Navarra), Spain in 1990. He received the Telecommunication Engineering degree from the Public University of Navarra, Spain, in 2014. He is currently working toward the Ph.D. degree in Electrical and Electronic Engineering at the Public University of Navarra. His research interests include the design and fabrication of passive components for the $\mathrm{THz}$ range, silicon micromachining, and surface micromachining with applications in high data rate wireless communication systems and $\mathrm{THz}$ imaging.

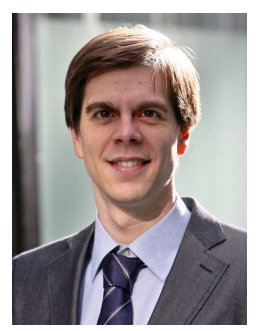

Israel Arnedo (S'05-M'11) was born in Tudela (Navarre), Spain, in 1980. He received the Telecommunication Engineering, M.Sc., and Ph.D. degrees from the Public University of Navarre, Pamplona, Spain, in 2004, 2007, and 2010, respectively.

$\mathrm{He}$ is currently an Associate Professor with the Electrical and Electronic Engineering Department, Public University of Navarre, where he has collaborated in research projects supported by the Spanish Government, the Natural Sciences and Engineering Research Council of Canada (NSERC), and the European Commission. He is cofounder of the spin-off company TAFCO Metawireless. 
$\mathrm{He}$ is a Reviewer for several international scientific journals. His research interests of the microwave, millimeter-wave, and terahertz fields include periodic structure devices, coupled-mode theory, inverse-scattering synthesis, and their applications in ultra-wideband (UWB) systems, space and satellite technology, and biomedical engineering research.

Dr. Arnedo was the recipient of a Formación de Profesorado Universitario (FPU) grant of the Spanish Ministry of Education and Science to support his doctoral research. In 2012 he was awarded with a José Castillejo grant of the Spanish Ministry of Education to support his postdoctoral research stay at the Institut d'Électronique de Microélectronique et de Nanotechnologie (IEMN), Villeneuve D'Ascq, France.

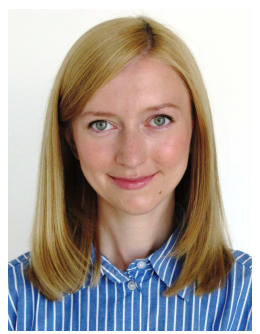

Magdalena Chudzik (S'08) was born in Warsaw, Poland, in 1984. She received the B.Sc. and M.Sc. degrees in electrical and computer engineering from the Warsaw University of Technology, Warsaw, Poland, in 2007 and 2009, respectively. In 2013, she received the Ph.D. degree in telecommunication engineering from the Public University of Navarre, Spain. Her research interests include coupled-mode theory, periodic structure devices, and passive devices in microwave, millimeter-wave and terahertz technologies

Dr. Chudzik was the recipient of a Formación de Profesorado Universitario (FPU) grant from the Spanish Ministry of Education and Science to support her doctoral research.

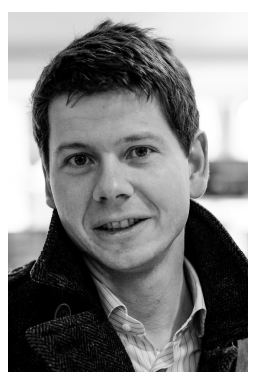

Michael Zedler studied electrical engineering at RWTH Aachen, Germany, receiving his Master degree in 2002. Next, he was with Munich University of Technology under supervision of Peter Russer, receiving his $\mathrm{PhD}$ in 2008 . Fields of topics included chip-integrated circuit/antenna design, numerical techniques, metamaterials. From 2008-2010 he was with University of Toronto, working in the team of George Eleftheriades in the field of antennas and metamaterials. Next, he joined Tesat Spacecom/Airbus DS, leading an engineering team since 2012 that works on multiplexers and components for satellite input/output sections. His present interests include future flexible payloads, 3D manufacturing, introduction of 6sigma concepts in engineering and production, automatisation of assembly and tuning.

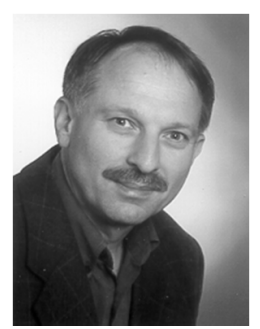

Franz-Josef Görtz was born in Hückelhoven, Germany, on October 08, 1954. He received the degree in electrical engineering Dipl. -Ing. (TH) from the Technical University RWTH Aachen in 1982.

He is currently with Tesat-Spacecom GmbH \& Co. KG, before Bosch Satcom, ANT Nachrichtentechnik, ATN and AEG-Telefunken, involved in development of passive products, filters and multiplexers. Since 1982 he designed, developed and implemented microwave flight hardware for several satellite programs covering L- to Ka-band frequencies. Actually he is working on input multiplexers for Ka-Band and his special interest is computer aided modelling, design and tuning of microwave filters. He has authored or coauthored several papers in technical journals and conferences and holds 5 patents in the area of microwave filters and multiplexers.

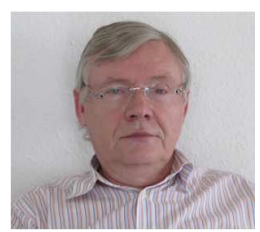

Rolf Jost was born in 1952 in Mönchengladbach, Germany. He received his Diploma in Physics from the University of Stuttgart in 1986. From 1986 to 2000 he was responsible for the development of passive microwave components for space application at ANT Nachrichtentechnik respectively at Bosch Telecom GmbH Backnang, Germany. Since 2001 he is program manager for the design and development of active and passive microwave equipment for space at TESAT Spacecom GmbH in Backnang, Germany.

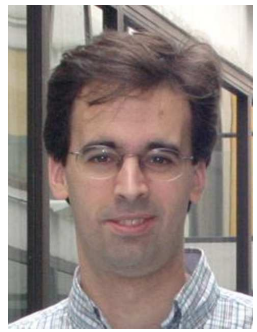

Txema Lopetegi (S'99 - M'03) was born in Pamplona, Navarre, in 1973. He received the M.Sc. and $\mathrm{Ph} . \mathrm{D}$. degrees in telecommunication engineering from the Public University of Navarre, in 1997 and 2002, respectively. Since 1997 he has been with the Electrical and Electronic Engineering Department, Public University of Navarre, first as Assistant Professor and since 2006 as Associate Professor. In 1999 and 2000, he was awarded a grant from the Spanish Ministry of Education to support the research in his doctoral thesis. During 2002 and 2003 he was with the Payload Systems Division, European Space Research and Technology Center (ESTEC), European Space Agency (ESA), at Noordwijk, The Netherlands, as post-doctoral researcher. He is also co founder of the spinoff company TAFCO Metawireless. His current research interests include metamaterials and synthesized structures in microwave and $\mathrm{THz}$ technologies, as well as coupled mode theory and synthesis techniques using inverse scattering.

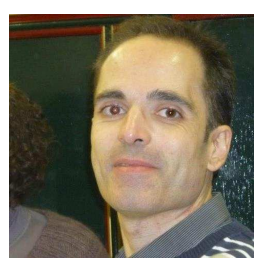

Miguel A. G. Laso (S'99-M'03) received the M.Sc. and Ph.D. degrees in Telecommunications Engineering from the Public University of Navarre, Navarre, Spain, in 1997 and 2002, respectively. From 1998 to 2001, he was with the Electrical and Electronic Engineering Department, Public University of Navarre, as a doctoral fellow student. He was an Assistant Professor in the same institution from 2001 to 2006 and an Associate Professor since 2006, always involved with teaching and research duties related to optical communications and microwave engineering. From 2002 to 2003, he was also a Research Fellow with the Payload Systems Division of the European Space Research and Technology Centre, European Space Agency, Noordwijk, The Netherlands. His current research interests comprise periodic structures, photonic/electromagnetic bandgap structures, Inverse Scattering problems, and synthesis techniques for filters, especially in the microwave and millimetre-wave frequency range, and their applications for telecommunications. He has published many papers in these fields and contributed to major conferences. He has also led projects with public and private funding.

Dr. Laso is a member of several professional and scientific international associations including the Institute of Electrical and Electronics Engineers (IEEE), the Optical Society of America (OSA), the International Society for Optics and Photonics (SPIE), and the American Society for Engineering Education (ASEE). He was the recipient of a grant from the Spanish Ministry of Education and Science to support his doctoral research at the Public University of Navarre from 1998 to 2001, and another one to support his postdoctoral research at the European Space Agency from 2002 to 2003 . He has been the recipient of several prizes including the Spanish National Prize to the Best Doctoral Dissertation in Telecommunications (2002) awarded by the Spanish Telecommunications Engineers Association (COIT/AEIT) and the Junior Research Award of the Public University of Navarre (2003). He has been also the recipient of the 2005 Spanish National Prize for the Best Project in Innovation in Higher Education awarded by the Spanish Ministry of Education and Science. He is also co founder of TAFCO MetaWireless S.L., a spin off company of the Public University of Navarre. 